\title{
Analisis Frekuensi Kemunculan Fase Dalam Sales Process Pada Penjualan Perlengkapan Masak Berbasis Mobile Chat (Studi Kasus: Forbento.Com)
}

\author{
Muchammad Fahmi Zamroni dan Arif Wibisono \\ Departemen Sistem Informasi, Fakultas Teknologi Informasi, Institut Teknologi Sepuluh Nopember \\ (ITS) \\ e-mail:mfahmizamroni@gmail.com,arif.wibisono@gmail.com
}

\begin{abstract}
Abstrak-Saat ini, aplikasi mobile chat muncul sebagai saluran penjualan dengan menggunakan tenaga penjualan untuk berhubungan dengan pelanggan, khususnya untuk memperbanyak penjualan. Berkembangnya mobile chat sebagai saluran penjualan menuntut para pelaku bisnis untuk terus melakukan perbaikan terhadap proses penjualan yang dilakukannya. Masalah yang muncul dari penjualan melalui mobile chat adalah fase-fase penjualan yang terjadi bersifat acak dan tidak terstruktur. Fase-fase sales process yang dimaksud adalah initiation, negotiation, execution dan acceptance. Sehingga, tidak mungkin jika semua fase-fase sales process terjadi secara lengkap dan berurutan dalam satu kali chat. Hal ini berpotensi membuat pelaku bisnis sulit menentukan prioritas perbaikan pada sales process, utamanya untuk meningkatkan penjualan. Penelitian ini bertujuan untuk menganalisis kemunculan fase-fase pada sales process. Kami menggunakan data forbento.com yang merupakan perusahaan berbasis internet yang menjual peralatan memasak di Indonesia. Forbento.com menggunakan 3 saluran mobile chat yang dijalankan oleh dua orang tenaga penjual. Saluran-saluran tersebut antara lain 1) penjual A (Whatsapp) 2) Penjual A (Blackberry messenger) 3) Penjual B (Whatsapp). Dalam penelitian ini, kami melakukan pengembangan fase-fase pada sales process untuk mendapatkan hasil yang lebih baik, antara lain making initial contact, exploration, bargaining, ordering, delivery product, payment, complaining, dan closing. Kemudian, kami memetakan percakapan di masing-masing saluran tersebut secara manual ke dalam fase-fase sales process. Kami menggunakan statistika deskriptif dan sequential pattern mining - algoritma prefixspan untuk menganalisis data selama 3 bulan. Hasil dari penelitian ini menunjukkan bahwa fase yang paling banyak dilakukan pada sales process dari segi probabilitas kemunculan fase, proporsi fase dalam satu kali percakapan dan frekuensi kemunculan adalah exploration. Pola urutan kemunculan fase yang paling sering terjadi adalah initiation, exploration, exploration, ordering, payment, delivery product, dan closing. Serta, proses tawar menawar memiliki pola urutan yang tidak tetap atau acak sesuai dengan kebiasaan pelanggan.
\end{abstract}

Kata Kunci-Action Workflow Theory, Mobile Chatting, Sales process, Statistika Deskriptif, Sequential Pattern Mining, PrefixSpan

\section{PENDAHULUAN}

$\mathrm{P}$ ROSES penjualan (sales process) yang baik penting untuk meningkatkan profit dan pendapatan (revenue) perusahaan. Proses penjualan didefinisikan sebagai proses dimana penjual mulai dari mempresentasikan produk yang ingin ditawarkan kepada pelanggan hingga pelanggan membeli produk tersebut [1]. Ada beberapa cara dalam menerapkan proses penjualan. Salah satunya adalah dengan menggunakan mobile chatting seperti whatsapp atau blackberry messenger. Dua aplikasi mobile chat ini merupakan aplikasi populer yang memiliki banyak pengguna aktif dari seluruh dunia. Dari data yang dilansir oleh statista.com, pada bulan April 2016, whatsapp memiliki sekitar satu miliar pengguna sedangkan blackberry messenger memiliki 100 juta pengguna yang aktif setiap bulannya di seluruh dunia [2]. Di Indonesia, aplikasi blackberry messenger dan whatsapp juga menjadi aplikasi sosial media yang paling banyak digunakan dengan persentase sebesar $19 \%$ dan $14 \%$ secara berturut-urut dari total responden yang di survei [3].

Saat ini, mobile chat muncul sebagai saluran penjualan dengan menggunakan tenaga penjualan untuk berhubungan dengan pelanggan, khususnya untuk meningkatkan penjualan. Mobile chat yang proaktif juga dapat memberikan dukungan kepada pelanggan dan dapat mengontrol kepuasan pelanggan terhadap perusahaan [4]. Kami menggunakan data forbento.com yang merupakan perusahaan berbasis internet yang menjual peralatan memasak di Indonesia. Forbento menggunakan 3 saluran mobile chat yang dijalankan oleh dua orang tenaga penjual. Saluran-saluran tersebut antara lain 1) penjual A (Whatsapp) 2) Penjual A (Blackberry messenger) 3) Penjual B (Whatsapp). Kemudian, kami memetakan percakapan di masing-masing saluran tersebut secara manual ke dalam fasefase sales process.

Masalah yang timbul dari penjualan melalui mobile chat adalah fase-fase penjualan yang terjadi adalah acak dan tidak terstruktur. Fase-fase pada proses penjualan yang dimaksud adalah initiation, negotiation, execution dan acceptance. Dimana setiap fase memiliki aktivitas-aktivitas yang berbeda satu sama lain. Dalam hal ini acak yang dimaksud adalah fase di dalam sales process tidak berurutan. Dalam sales process tersebut tidak semua fase dilalui dan tidak semua fase memiliki frekuensi kemunculan yang sama. Hal ini terjadi karena sifat transaksi adalah customer-driven. Di dalam transaksi yang bersifat customer-driven, pelanggan memegang peranan lebih aktif di bandingkan tenaga penjual utamanya dalam memulai diskusi dan memilih topik [5,6]. Di sini, tenaga penjual lebih bersifat pasif yaitu menjawab sesuai dengan pertanyaan pelanggan [6]. Dengan demikian, kecil kemungkinan terjadinya 
semua fase pada proses penjualan secara berurutan dalam satu chat. Hal ini berpotensi mempersulit manajer untuk menentukan perbaikan prioritas dalam proses penjualan, terutama untuk meningkatkan penjualan.

Oleh karena itu penelitian ini bertujuan untuk menganalisis frekuensi kemunculan fase-fase pada sales process. Fase ini adalah fase yang sering dialami pelanggan ketika berhubungan dengan tenaga penjual. Dengan memahami tahapan pada sales process, kita dapat melakukan perbaikan pada masing-masing fase untuk meningkatkan pengalaman pelanggan (customer experience).

\section{DASAR TEORI}

\section{A. Mobile Commerce}

Mobile commerce merupakan sistem perdagangan elektronik baik barang maupun jasa dengan menggunakan peralatan mobile, seperti telepon genggam, smart phone, personal digital assistant, dan lain-lain [7]. Dengan mobile commerce pembeli dapat melakukan transaksi perdagangan elektronik dengan lebih fleksibel, mudah dan praktis tanpa memperhatikan tempat dan waktu. Sehingga mobile commerce sebagai emerging technology dimanfaatkan pembeli ketika sedang berpindahpindah lokasi pada saat melakukan perdagangan elektronik [7, 8].

\section{B. Action Workflow Theory}

Action-Workflow adalah sebuah sistem kerja yang berfokus pada koordinasi antar orang [9]. Action-Workflow dapat juga dilihat sebagai kerangka kerja sebuah proses bisnis dan alur kerja dalam menganalisis dan metode pemodelan [10]. Berdasarkan Marlon Dumas, Action-Workflow process pada transaksi finansial dapat dibagi menjadi 4 fase yaitu initiation, negotiation, execution, dan acceptance [11].

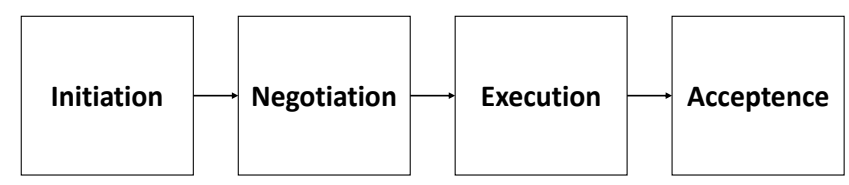

Gambar 1. Action Workflow Theory

Gambar 1 menunjukkan tahapan yang dilakukan pada action workflow theory, yang dimulai dari initiation hingga accepatnce. Tahapan initiation merupakan tahapan dimana pelanggan melakukan inisiasi dengan menghubungi penjual terkait dengan produk atau layanan yang ditawarkan. Tahapan negotiation dilakukan pada saat proses negosiasi dimulai antara pelanggan dan penjual. Proses ini dilakukan untuk menentukan kesepakatan bersama antara keduanya. Tahapan execution terjadi pada saat penjual menyampaikan(delivery) produk kepada pelanggan. Tahapan acceptance apabila pelanggan sudah menerima produk dari penjual.

\section{Sales process}

Sales process merupakan pendekatan sistematis yang digunakan untuk menjual produk atau layanan kepada pelanggan [12]. Sales process mendefinisikan cara terbaik dalam melakukan penjualan untuk mencapai tujuan dengan mengoptimalkan pekerjaan dari tenaga penjual [7]. Dengan mendefinisikan sales process dengan jelas maka penjual telah melakukan inisiasi kegiatan yang membantu mereka untuk lebih efektif dan produktif dalam memahami pelanggan dalam melakukan pembelian [12,13]. Pakar Quality Joseph Juran mengatakan bahwa tidak mungkin prinsip kualitas dan process engineering tidak bekerja di sales process [14]. Dengan sales process yang baik tenaga penjual dituntut untuk bekerja dengan maksimal dengan waktu yang relatif singkat [15]. Penjualan secara efektif dapat dilakukan oleh tenaga penjual untuk mencapai target penjualan tersebut.

Pada penelitian ini, sales process yang digunakan mengacu kepada sudut pandang proses pembelian yang dilakukan oleh pelanggan. Adapun fase-fase yang ada di dalamnya adalah Recognition of need, evaluation of option, resolution of concern, purchase, dan implement [16]. Recognition of need merupakan fase dimana pelanggan sedang melakukan pencarian kebutuhan terhadap produk atau layanan. Evaluation of option adalah fase ketika pelanggan sudah mengetahui kebutuhannya dan sedang melakukan evaluasi terhadap pilihan-pilihan produk atau layanan yang ditawarkan. Fase ketiga yaitu resolution of concern, fase ini menandakan pelanggan sedang menentukan pilihan dan kepastian dalam pemilihan produk. Purchase adalah fase pembelian produk oleh pelanggan. Implement merupakan fase yang diantaranya terjadi proses pembayaran, pengiriman dan penerimaan barang oleh pelanggan.

\section{Statistika Deskriptif}

Statistika deskriptif adalah metode yang digunakan untuk mendeskripsikan kumpulan data atau hasil pengamatan sehingga memberikan informasi yang berguna [17]. Data yang digunakan untuk metode ini dapat bersumber dari banyak hal, yaitu survei, jejak pendapat, hasil wawancara, hasil pengamatan, dll. Data-data yang dikumpulkan tersebut disajikan dalam bentuk tabel maupun grafik agar mudah dimengerti, menarik dan lebih informatif bagi pihak lain.

Penggunaan metode ini untuk membantu peneliti dalam memaparkan data dengan baik agar mudah diinterpretasikan. Dalam melakukan pendeskripsian data, tabel frekuensi adalah cara penyajian yang paling umum digunakan. Sedangkan untuk menampilkan nilai pemusatan bisa menggunakan jenis ukuran rata-rata, median dan modus [18].

\section{E. PrefixSpan}

Algoritma prefixspan merupakan salah satu algoritma dalam sequential pattern mining. Sequence adalah urutan-urutan dari elemen yang terjadi. Contoh dari sequence adalah $\mathrm{t}=\left\langle\mathrm{f}_{1}, \mathrm{f}_{2}, \mathrm{f}_{3}, \ldots\right.$, $f_{n}>$, dengan $f$ adalah elemen. Panjang dari $|t|$ tergantung pada banyaknya elemen pada sequence tersebut. Sedangkan k merupakan banyaknya kejadian pada f. Algoritma prefixspan atau Prefix-projected Sequential Pattern Mining merupakan salah satu bentuk tree dan structure[19]. Prefixspan dapat menemukan semua pola dari setiap sequence yang terjadi. Dalam implementasinya, prefixspan dapat mengurangi penggunaan database karena penggunaan memori lebih sedikit dan proses pencarian pola sequence lebih cepat[20]. Jika dibandingkan dengan aprioriall, secara durasi eksekusi, skalabilitas, reliabilitas, dan utilitas memori, prefixspan lebih baik[21]. 


\section{METODOLOGI}

Pengerjaan studi ini tersusun atas beberapa langkah yang sistematis. Langkah-langkah pengerjaan studi dari awal hingga akhir ditunjukkan pada Gambar 2. Metodologi Penelitian.

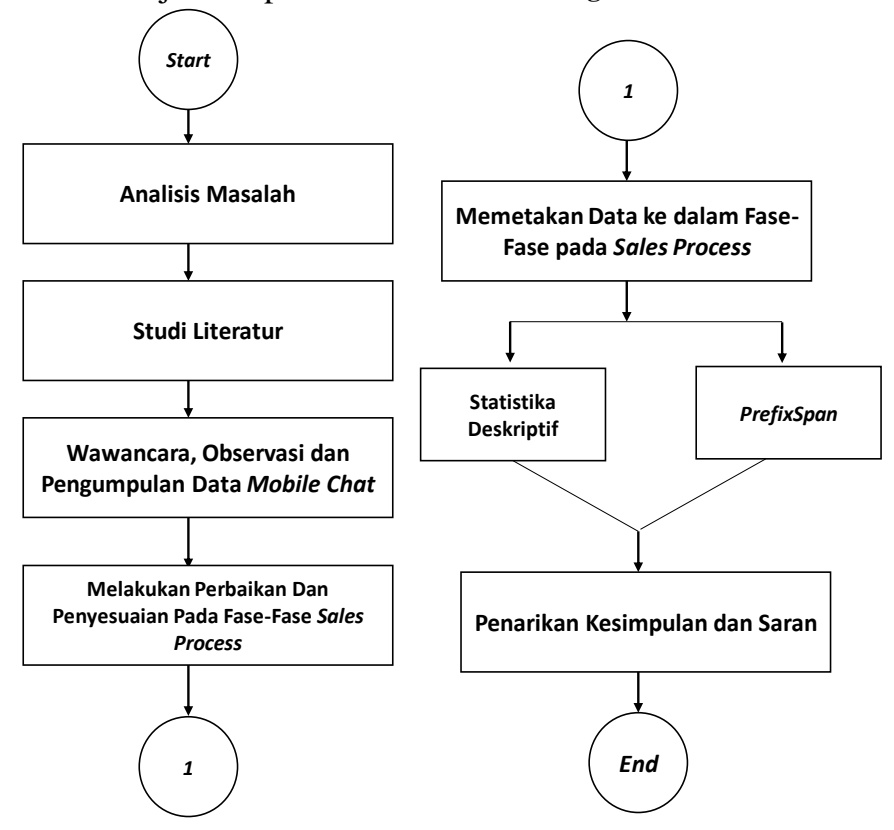

Gambar 2. Metodologi Penelitian

\section{HASIL DAN ANALISIS}

\section{A. Pengembangan Fase pada Proses Penjualan}

Pada bagian ini, dijelaskan mengenai pengembangan fasefase proses penjualan yang didasarkan pada action workflow theory sebagai fase umum pada proses penjualan. Pengembangan yang dilakukan dengan tujuan agar proses analisis pada transaksi penjualan melalui mobile chat lebih baik. Hasil dari pengembangan fase yang dilakukan yaitu:

\section{Making initial contact}

Making the initial contact adalah kegiatan yang dilakukan antara pelanggan dan penjual yang diinisiasi oleh pelanggan kepada penjual maupun sebaliknya. Making the initial contact merupakan proses yang dilakukan untuk memulai proses penjualan. Ciri-ciri percakapan yang melakukan proses ini yaitu percakapan berisi tentang komunikasi yang diawali dengan kalimat sapaan yang biasa terjadi di awal percakapan.

2. Exploration

Exploration adalah proses awal yang dilakukan pada fase negosiasi. Proses eksplorasi merupakan proses dimana pelanggan ingin memperoleh sebuah informasi dari penjual tentang produk yang dijual oleh penjual. Proses eksplorasi juga terjadi pada saat penjual ingin mengetahui banyak tentang kebutuhan pelanggan dan apa yang mereka inginkan. Ciri-ciri percakapan yang melakukan proses ini yaitu percakapan berisi tentang ketersedian produk, detail layanan, dan detail produk.

3. Bargaining

Bargaining merupakan proses inti dari fase negosiasi. Sub fase barganing atau tawar menawar adalah kegiatan yang sering dilakukan pada proses penjualan untuk mendapatkan kesepakatan bersama. Tawar menawar lebih banyak dilakukan oleh pembeli untuk mendapatkan produk yang sesuai dengan kebutuhan. Ciri-ciri percakapan yang melakukan proses ini yaitu percakapan berisi tentang tawar harga produk, diskon, lama pengiriman dan biaya kirim.

4. Ordering

Ordering adalah proses pemesanan barang atau jasa yang dilakukan oleh pembeli kepada penjual baik itu secara langsung atau melalui media. Dalam proses penjualan melalui mobile chat, proses order dilakukan dengan cara menghubungi penjual secara langsung melalui mobile chat. Proses pesanan berbeda dengan proses pembelian. Proses pesanan terbatas pada pemesanan produk atau jasa yang dilakukan oleh pembeli kepada penjual. Pada proses pemesanan belum terjadi pembayaran produk. Sehingga, proses ini dikatakan berbeda degan proses pembelian produk. Ciri-ciri percakapan yang melakukan proses ini yaitu percakapan berisi tentang inisiasi order dan konfirmasi order.

5. Delivery Product

Product Delivery adalah proses penyerahan produk dari penjual kepada pembeli. Ciri-ciri percakapan yang melakukan proses ini yaitu percakapan berisi tentang konfirmasi pengiriman produk dan tracking pengiriman produk.

6. Payment

Payment adalah proses pembayaran yang oleh pelanggan kepada penjual atas transaksi jual beli barang atau jasa. Ciriciri percakapan yang melakukan proses ini yaitu percakapan berisi tentang informasi pembayaran dan konfirmasi pembayaran.

7. Complaining

Complaining atau komplain pada proses penjualan merupakan bagian dari bentuk komunikasi yang dilakukan oleh pelanggan kepada penjual. Pelanggan melakukan komplain karena merasa terjadi ketidaksesuaian terhadap produk atau jasa yang diterima. Ciri-ciri percakapan yang melakukan proses ini yaitu percakapan berisi tentang informasi keluhan produk, keluhan layanan, dan keluhan attitude pegawai.

8. Closing

Pada proses penjualan, closing merupakan kegiatan terakhir yang dilakukan oleh penjual dan pembeli. Pada sub fase ini terjadi proses pemberian feedback antara pembeli dan penjual. Ciri-ciri percakapan yang melakukan proses ini yaitu percakapan berisi tentang informasi kepuasan pelanggan.

\section{B. Pemetaan Data Percakapan Penjualan}

Pada tahap ini, setiap data percakapan melalui mobile chat dipetakan berdasarkan topik yang dibahas oleh penjual dan pembeli sesuai urutan waktu ke dalam sub-fase proses penjualan. Adapun sebuah percakapan disebut satu topik bahasan adalah sebagai berikut:

1. Percakapan yang dilakukan antara penjual dan pembeli jelas dan bisa dimengerti

2. Percakapan yang dilakukan antara penjual dan pembeli berhubungan dengan proses penjualan dan bukan percakapan seputar pribadi 
3. Topik percakapan berada dalam satu urutan waktu yang sama dan membahas topik tentang produk atau layanan yang sama.

4. Apabila topik yang dibahas dalam percakapan tersebut berbeda produk atau layanan dari topik sebelumnya, maka percakapan tersebut dapat dikatakan berbeda topik.

Data transkrip percakapan dipetakan ke dalam bentuk file excel dengan format seperti berikut:

Tabel 1.

Data Transkrip Percakapan

\begin{tabular}{ll}
\hline \hline Nama kolom & Deskripsi \\
\hline $\begin{array}{l}\text { Nama Akun / No. } \\
\text { telepon }\end{array}$ & $\begin{array}{l}\text { Berisi nama akun } B B M \text { pelanggan atau nomor } \\
\text { telepon Whatsapp pelanggan }\end{array}$ \\
Media & $\begin{array}{l}\text { Berisi informasi media yang digunakan, } B B M \\
\text { atau Whatsapp }\end{array}$ \\
Admin & $\begin{array}{l}\text { Berisi Informasi nama tenaga penjual yang } \\
\text { bertugas }\end{array}$ \\
Tanggal & Berisi tanggal transaksi \\
Proses penjualan & Berisi urutan proses penjualan yang terdiri dari \\
& beberapa sub fase berdasarkan urutan waktu \\
\hline \hline
\end{tabular}

C. Analisis Frekuensi Kemunculan Fase

Sub bab ini menjelaskan tentang analisis frekuensi fase penjualan yang terdiri dari:

1. Probabilitas kemunculan masing-masing sub fase

Pada bagian ini, peneliti ingin mengetahui probabilitas kemunculan sub fase pada percakapan penjualan. probabilitas kemunculan sub fase yang dimaksud adalah berapa persen kemungkinan sub fase tersebut muncul pada saat percakapan penjualan terjadi.

\section{Grafik Probabilitas Kemunculan Sub Fase}

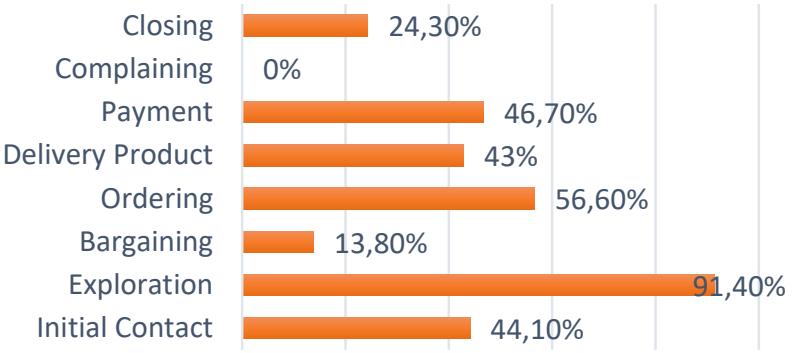

Gambar 3. Grafik Probabilitas Kemunculan Sub Fase

Berdasarkan Gambar 3. Grafik Probabilitas Kemunculan Sub FaseGambar 3, sub fase exploration memiliki probabilitas kemunculan paling tinggi yaitu sebesar 91,40\%. Selanjutnya, sub fase ordering memiliki probabilitas kemunculan sebesar $56,6 \%$, sub fase payment memiliki probabilitas kemunculan sebesar $46,70 \%$, sub fase making initial contact memiliki probabilitas kemunculan sebesar $44,10 \%$, sub fase delivery product memiliki probabilitas kemunculan sebesar 43\%, sub fase closing memiliki probabilitas kemunculan sebesar $24,30 \%$, sub fase bargaining memiliki probabilitas kemunculan sebesar $13,80 \%$, dan sub fase complaining tidak terjadi sama sekali. Hal ini menunjukkan bahwa dari seluruh percakapan penjualan, sub fase exploration yang paling sering dilakukan. Dari 152 percakapan penjualan 91,40\% diantaranya pernah membicarakan tentang sub fase exploration. Hal ini menandakan bahwa sub fase exploration penting dilakukan oleh penjual dan pembeli dalam proses penjualan.

2. Proporsi masing-masing sub fase dalam satu kali transaksi Pada bagian ini, peneliti ingin mengetahui proporsi masingmasing sub fase pada setiap percakapan penjualan melalui mobile chat. Proporsi sub fase yang dimaksud adalah seberapa besar rasio topik yang membicarakan sub fase tersebut dibanding keseluruhan topik yang dibahas dalam satu kali percakapan penjualan.

\section{Grafik Rata-Rata Proporsi Sub Fase setiap Percakapan Penjualan}

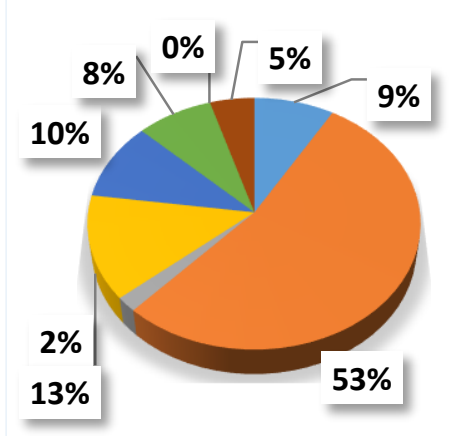

$$
\begin{aligned}
& \text { Initial } \\
& \text { Contact } \\
& \text { Exploration } \\
& \text { Bargaining } \\
& \text { Ordering } \\
& \text { Delivery } \\
& \text { Product } \\
& \text { Payment }
\end{aligned}
$$

Gambar 4. Grafik Rata-rata Proporsi Sub Fase setiap Percakapan Penjualan

Hal ini menunjukkan bahwa dalam satu kali transaksi sub fase eksplorasi paling banyak dilakukan oleh penjual dan pembeli. Sub fase kedua dan ketiga yang paling banyak dibicarakan pada satu kali transaksi penjualan adalah sub fase ordering dan delivery product.

Pernyataan tersebut didukung juga oleh hasil wawancara yang dilakukan dengan pemilik bisnis. Budaya pembeli di Indonesia dalam membeli produk secara online masih butuh untuk bertanya kepada pembeli baik itu tentang produk atau layanan yang dijual. Sehingga proses eksplorasi akan lebih banyak dilakukan pembeli dalam mobile chat. Begitu juga untuk masalah pemesanan produk dan pengiriman barang, hal ini masih dipengaruhi oleh perilaku pembeli dalam proses penjualan.

3. Frekuensi kemunculan masing-masing sub fase penjualan pada proses penjualan.

Pada bagian ini, peneliti ingin mengetahui frekuensi kemunculan masing-masing sub fase yang terjadi pada proses penjualan melalui mobile chat. Frekuensi kemunculan fase yang dimaksud adalah seberapa sering topik percakapan yang dilakukan oleh penjual dan pembeli untuk masing-masing sub fase dalam satu kali transaksi penjualan. Satuan dari frekuensi kemunculan fase adalah $\mathrm{x}$ (kali). Pertanyaan yang ingin dijawab dalam penelitian ini adalah berapa kali topik percakapan tentang masing-masing sub fase yang paling sering dilakukan pada proses penjualan. Berikut adalah hasil dari frekuensi kemunculan fase yang paling sering dilakukan. 
Tabel 2.

Rangkuman Hasil Frekuensi Kemunculan Fase

\begin{tabular}{ll}
\hline \multicolumn{1}{c}{ Sub Fase } & $\begin{array}{c}\text { Frekuensi Kemunculan Fase yang } \\
\text { Sering Dilakukan }\end{array}$ \\
& \multicolumn{1}{c}{1 kali } \\
Making Initial Contact & 2 kali hingga 3 kali \\
Exploration & 1 kali \\
Bargaining & 1 kali hingga 2 kali \\
Ordering & 1 kali hingga 2 kali \\
Delivery Product & 1 kali hingga 2 kali \\
Payment & Tidak pernah terjadi \\
Complaining & 1 kali \\
Closing &
\end{tabular}

Dari rangkuman hasil pada 2, fase yang paling besar frekuensi kemunculannya adalah fase exploration yaitu 2 hingga 3 kali setiap kemunculannya. Kemudian dilanjutkan dengan fase ordering, delivery product, dan payment dengan frekuensi 1 hingga 2 kali setiap percakapan penjualan terjadi. Making initial contact, bargaining dan closing hanya terjadi 1 kali. Serta, sub fase complaining yang tidak terjadi sama sekali dalam studi kasus ini.

D. Analisis Pola Urutan Proses Penjualan

Pada bagian ini, peneliti ingin mengetahui informasi mengenai urutan-urutan fase yang sering muncul pada proses penjualan melalui mobile chat. Pada penelitian ini, peneliti ingin mendapatkan seluruh pola urutan yang mungkin terjadi pada proses penjualan. Penggunaan algoritma ini diharapkan membantu peneliti dalam memberikan informasi dan gambaran mengenai pola urutan yang sering muncul pada proses penjualan.

Tabel 3.

Hasil Pola Urutan Fase yang Terbentuk

\begin{tabular}{|c|c|}
\hline Pola Urutan Fase yang Terbentuk & $\begin{array}{ll}\text { Jumlah } & \text { Percakapan } \\
\text { Penjualan } & \\
\end{array}$ \\
\hline 1 & 67 \\
\hline 12 & 59 \\
\hline 122 & 44 \\
\hline 1222 & 28 \\
\hline 12222 & 22 \\
\hline 122222 & 14 \\
\hline 1222222 & 8 \\
\hline 12222265 & 10 \\
\hline 122224 & 17 \\
\hline 1222242 & 9 \\
\hline 12222424 & 9 \\
\hline$\ldots$ & $\ldots$ \\
\hline 665558 & 8 \\
\hline
\end{tabular}

Hasil yang ditunjukkan dari tabel 3 adalah hasil pengolahan pola urutan fase yang menghasilkan lebih dari 300.000 pola urutan fase yang terbentuk. Dari data-data tersebut dilakukan analisis dengan mempertimbangkan jumlah percakapan penjualan yang terbanyak dari total percakapan penjualan yang terjadi.

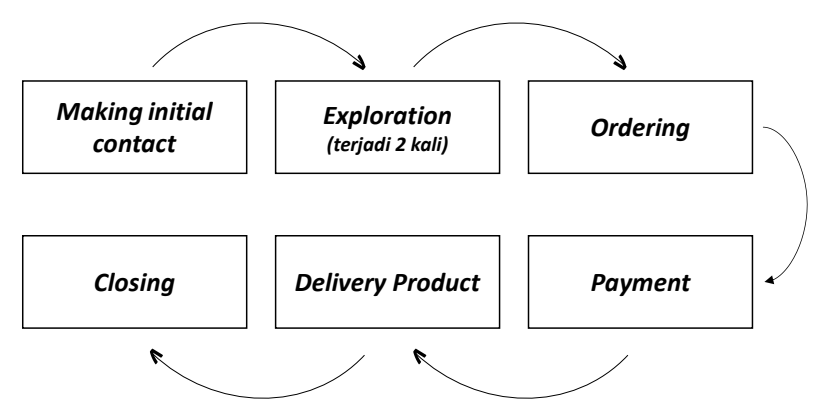

Gambar 5. Hasil Rangkuman Pola Urutan Fase dengan Algoritma PrefixSpan

Berdasarkan Gambar 5, hasil yang didapatkan dari pengolahan dengan algoritma prefixspan menampilkan pola urutan proses penjualan dengan urutan lain initiation, exploration, exploration, ordering, payment, delivery product, dan closing.

\section{Pola 1}
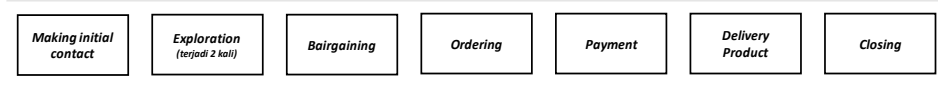

Pola 2
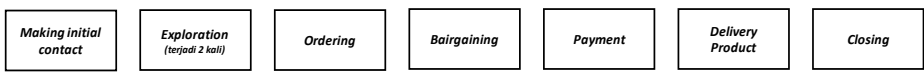

Pola 3

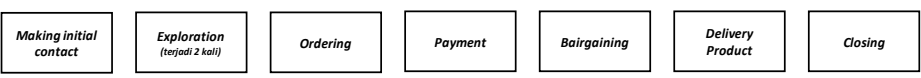

Gambar 6. Hasil Rangkuman Pola Urutan Fase dengan Algoritma PrefixSpan

Dari hasil yang ditampilkan, fase kemunculan sub fase bargaining cenderung kecil yaitu sekitar $10 \%$ dari semua percakapan penjualan yang terjadi. Apabila sub fase bargaining terjadi maka terdapat 3 pola urutan berbeda yang sering terjadi pada proses penjualan, yaitu:

1. Pola 1 merupakan pola urutan dimana sub fase bargaining dilakukan setelah sub fase exploration dan sebelum sub fase ordering. Proses tawar menawar pada pola ini dilakukan oleh pelanggan sebelum memutuskan untuk memesan produk. Berdasarkan hasil wawancara dengan pemilik, kondisi seperti ini masih belum bisa memprediksi keputusan pelanggan dalam melakukan pembelian produk. Jika harga yang ditawar sesuai dengan harapan pelanggan, maka kemungkinan pelanggan melakukan pemesanan produk semakin besar.

2. Pola 2 merupakan pola urutan dimana sub fase bargaining dilakukan setelah sub fase ordering dan sebelum sub fase payment. Proses tawar menawar pada pola ini dilakukan oleh pelanggan setelah melakukan pemesanan dalam rangka menunggu proses pembayaran. Proses tawar menawar pada pola ini dilakukan pelanggan untuk mendapatkan harga yang lebih murah dari harga pesanan awal. Motivasi pelanggan dalam melakukan tawar menawar pada pola ini yaitu untuk mencoba keberuntungan agar mendapatkan harga yang lebih murah. Namun apabila tidak terjadi, biasanya pelanggan akan tetap melakukan pemesanan dengan harga pesanan awal. 
3. Pola 3 merupakan pola urutan dimana sub fase bargaining dilakukan setelah sub fase payment. Pola ini dilakukan pada saat pembahasan topik payment atau setelah payment. Dimana yang penawar yang dilakukan terkait dengan harga yang harus dibayarkan. Hampir sama dengan pola 2 , motivasi pelanggan dalam melakukan tawar menawar pada pola ini untuk mencoba keberuntungan agar mendapatkan harga yang lebih murah.

\section{KESIMPULAN}

Berikut ini adalah beberapa kesimpulan yang bisa diambil dari penelitian studi ini:

a. Dalam proses penjualan fase yang paling banyak dilakukan dari segi probabilitas kemunculan fase, proporsi fase dalam satu kali percakapan dan frekuensi kemunculan adalah exploration.

b. Pola urutan kemunculan fase yang paling sering terjadi adalah initiation, exploration, exploration, ordering, payment, delivery product, dan closing.

c. Tawar menawar jarang terjadi karena penjual selalu memberikan informasi diskon saat exploration.

d. Proses tawar menawar memiliki pola urutan yang tidak tetap atau acak bergantung pada kebiasaan pelanggan.

e. Pada penelitian ini sub fase complaining tidak terjadi.

\section{SARAN}

Saran penulis untuk penelitian selanjutnya sebagai berikut:

a. Untuk penelitian selanjutnya, studi kasus yang digunakan sebagai objek penelitian lebih dari satu perusahaan.

b. Data percakapan penjualan yang digunakan lebih dari dua bulan untuk mendapatkan hasil yang lebih dalam.

c. Penelitian selanjutnya dapat melakukan analisis dari sisi pelanggan, sehingga data penelitian bisa berasal dari banyak sumber dengan sudut pandang yang berbeda.

\section{DAFTAR PUSTAKA}

M. Webb, Sales Process Excellence: Increase Customer Value,
Accelerate Your Sales Funnel, Grow Your Business. Sales Performance Consultants, 2014.

[2] www.statista.com, "Most popular messaging apps 2016 | Statistic," 2016. .

[3] wearesocial.com, "Digital in 2016 - We Are Social Singapore." .

[4] Forrester, "Making Proactive Chat Work," 2010.

[5] B. Taylor, Customer driven change: what customers know, employees think, and managers overlook. Brown Books Pub. Group, 2009.

[6] M. Lindgren, J. Jedbratt, and E. Svensson, Beyond Mobile: People, Communications and Marketing in a Mobilized World - M. Lindgren, J. Jedbratt, E. Svensson. Springer, 2002.

[7] P. C. Deans, E-commerce and M-commerce technologies. IRM Press, 2005.

[8] G. Elliott and N. Phillips, Mobile commerce and wireless computing systems. Pearson/Addison Wesley, 2004.

[9] K. van Hee, Workflow Management: Models, Methods, and Systems. MIT Press, 2004.

[10] R. Medina-mora, R. Medina-mora, T. Winograd, R. Flores, and O. Flores, "The Action Workflow approach to workflow management technology," Proc. ACM CSCW'92, pp. 281--288, 1992.

[11] M. Dumas, M. La Rosa, J. Mendling, and H. A. Reijers, Fundamentals of Business Process Management. Berlin, Heidelberg: Springer Berlin Heidelberg, 2013.

[12] H. C. (Sandy) Waters III, Sales - What A Concept!: A Guidebook for Sales Process Performance Improvement. Lulu.com, 2011.

[13] B. N. Ten Haken, Do YOU Mean Business?: Technical / NonTechnical Collaboration, Business Development and You. BookBaby, 2012.

[14] J. M. (Joseph M. . Juran and F. M. Gryna, Juran's quality control handbook. McGraw-Hill, 1988.

[15] M. J. Webb and T. Gorman, Sales and Marketing the Six Sigma Way: Improve Your Sales Process, Win More Customers, Lower Costs \& Boost Margins. BookBaby, 2006.

[16] A. A. Zoltners, P. Sinha, S. E. Lorimer, and Palgrave Connect (Online service), Sales force design for strategic advantage. Palgrave Macmillan, 2004.

[17] R. E. Walpole, Introduction to statistics. Macmillan, 1982

[18] A. Saefuddin and K. A. Notodiputro, Statistika Dasar. Jakarta: Grasindo, 2009.

[19] S. Kirono, "SPATIO-TEMPORAL SEQUENTIAL PATTERN MINING UNTUK DETEKSI DINI KEBAKARAN PADA LAHAN GAMBUT DI PROVINSI RIAU."

[20] J. Pei et al., "Mining Sequential Patterns by Pattern-Growth: The PrefixSpan Approach."

[21] R. Soelaiman and D. Saputra, "Analisis Kinerja Algoritma Prefixspan Dan Aprioriall Pada Penggalian Pola Sekuensial," vol. 2006, no. Snati, 2006 